Case Report

\title{
NECROBIOTIC XANTHOGRANULOM A PRESENTING AS A CLINICAL VARIANT WITHOUT PARAPROTEINEMIA
}

\author{
Michelle Mathias ${ }^{1}$,Harish S Permi ${ }^{2}$, Padma Shetty ${ }^{3}$, \\ Jayaprakash Shetty $K^{4}$, B.S. Girish ${ }^{5}$ \\ ${ }^{1}$ Associate Professor, ${ }^{2}$ Assistant Professor, ${ }^{3}$ Professor, ${ }^{4}$ Professor and HOD, Department of Pathology, \\ ${ }^{5}$ Associate Professor, Department of Dermatology, \\ K.S. Hegde M edical Academy, Nitte University, Derlakatte, M angalore ,INDIA.
}

Correspondence:

Dr. Michelle Mathias,

Associate Professor, Department of Pathology, K.S. Hegde M edical Academy, Nitte University, Derlakatte, M angalore - 575018, INDIA.

Mobile No. : 9449022921 E-mail : path.michelle@gmail.com

\begin{abstract}
:
Necrobiotic xanthogranuloma is a rare granulomatous disease involving skin and subcutaneous tissues. A 61 year old woman presented with a 5 year history of enlarging plaques around both eyelids.it was associated with diminished vision in both eyes. The lesions are often bilateral,symmetrical and ophthalmologic complications are observed. A histopathological examination showed features of necrobiotic xanthogranuloma. Necrobiotic xanthogranuloma is usually associated with paraproteinemia which was not seen in our case.The pathogenesis remains unclear. Although there is no first line of treatment, reports have shown variable benefits with chemotherapeutic agent and steroids.
\end{abstract}

Keywords : necrobiotic xanthogranuloma, necrobiosis.

\section{Introduction:}

Necrobiotic xanthogranuloma(NXG) is characterized by multiple, sharply demarcated nodules and plaques which have a violaceous to red to orange-yellow appearance. There may be central atrophy, ulceration and telangiectasia. These lesions occur around the eyes and face but may occur in the trunk and limbs. These lesions may be chronic and may be progressive. It is usually associated with paraproteinemia, bone marrow plasmacytosis, hypocomplementemia and hyperlipidemia.

\section{Case Report:}

A 61 year old female came with raised non tender lesions around both eyes since 5 years. Initially the lesion started as a small papule around both eyelids.it was painless and gradually to the present state. Local examination of the lesion showed multiple non tender diffuse swellings in the periorbital region, which was soft to firm in consistancy. Laboratory investigations showed a mildly elevated lipid profile. The hemoglobin level was $7.7 \mathrm{gms} / \mathrm{dl}$.,the packed cell volume was26.Aperipheral smear report showed dimorphic anaemia with eosinophilia. The erythrocyte sedimentation rate was $45 \mathrm{~mm} / \mathrm{hr}$.protein electrophoresis was done twice and there was no increase in paraproteins. The lesion was excised and sent for histopathological examination. The lesion was grossly yellow. histopathologic examination shows granulomatous infilterate comprising of foamy histiocytes, in focal aggregates and intersecting bands. plenty of giant cellsare seen of both the foreign body type and touton type. Places show dense aggregates of lymphocytes forming germinal centres. There are areas of necrobiosis. The diagnosis of necrobiotic xanthogranuloma was made.

\section{Discussion :}

Necrobiotic xanthogranuloma(NXG) is a rare progressive disease showing destructive cutaneous lesions and usually a close association with paraproteinemia. 
NXG is a disease of adults usually seen in the sixth decade of life. The lesions have a characteristic yellow color $(1,2,3)$. The most common involvement is the faceparticularly the periorbital region( $85 \%$ of cases) . the trunk and proximal extremities are other affected sites. Ophthalmologic complications are seen in $50 \%$ of cases include orbital mass, conjunctival involvement keratitis, scleritis and uveitis(1)

NXG can involve other sites like lungs, kidneys, liver, spleen, intestines, skeletal muscle and central nervous system $(1,4,5)$. Paraproteinemia is closely associated with nxg, with approximately $80 \%$ of patients demonstrating a monoclonal gammapathy on serum protein electrophoresis. A case report discusses a case of $n \times g$ without paraproteinemia as seen in our case. there was no signs of paraproteinemia, malignancy or new skin lesionsin our case, in the year to follow(12).
Histopathologic examination shows a xanthogranuloma with areas of necrobiosis, comprising of degenerated collagen that infiltrates into the mid dermis and subcutaneous fat. Multiple foamy histiocytes, foreign body giant cell, touton giant cells, cholesterol clefts and lymphoid follicles are also seen $(1,2)$.

Treatment of NXG - improvement was seen in skin lesions with chlorambucil, melphalan, localized radiotherapy, systemic glucocorticoids, inteferons $2 a$ and plasmapheresis $(1,6,7,8,9,10,11)$. In our case improvement was seen with steroids.

To conclude - with the characteristic histopathological picture, the diagnosis of necrobiotic xantho granuloma should be considered even in the absence of paraproteinemia.

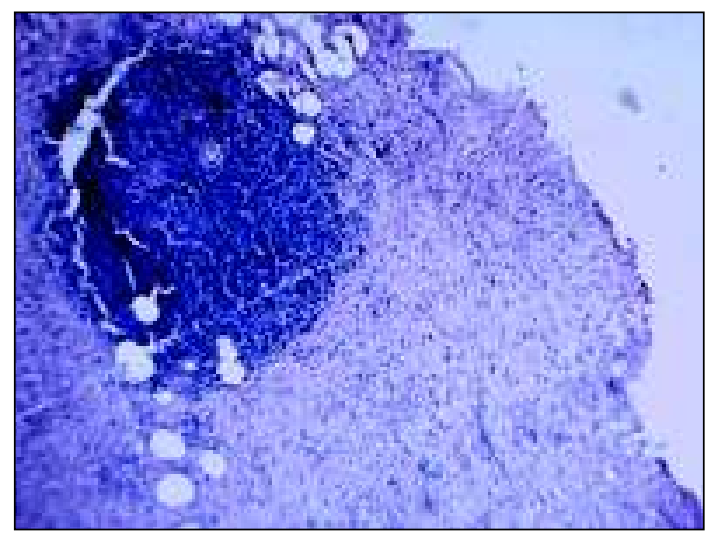

Fig 1-a lymphoid follicle is seen surrounded by foamy histiocytes(H\&EX100)

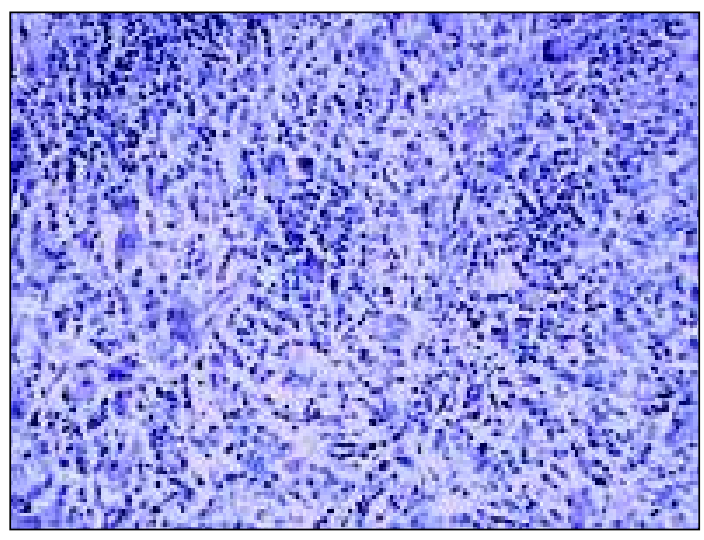

Fig 2-foreign body giant cells and touton giant cells seen amidst lymphocytes and histiocytes(H\&EX400)

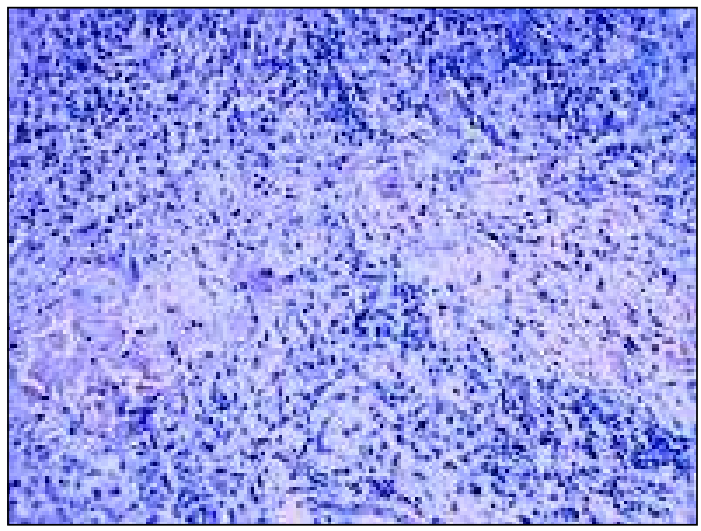

Fig3-area of necrobiosis seen in the centre surrounded by lymphocytes and histiocytes. (H\&EX400) 


\section{References:}

1. Wee SA, Shupack Jerome G. Necrobiotic xanthogranuloma. Dermatology online journal 2005(4):24

2. Finan MC,WinklemanRK. Necrobiotic xanthogranuloma with paraproteinemia: a review of 22 cases.M edicine 1986;65:376

3. Mehregan DA,Winkleman RK.Necrobiotic xanthogranuloma. Arch Dermatol 1992;128:94

4. Winkleman RK, et al. Giant cell granulomatous pulmonary and myocardial lesions in necrobiotic xanthogranuloma with paraproteinemia. Mayo Clin Proc 1991;66: 1222

5. Shah KC,et al.necrobiotic xanthogranuloma with cutaneous and cerebral manifestations.J. Neurosurg 2004;100:1111

6. Machado S,et al.cutaneous necrobiotic xanthogranuloma-sucessfully treated with low dose chlorambucil.EurJ dermatol 2001;11:458
7. Macfarlane AW,Verbov JL.Necrobiotic xanthogranuloma with paraproteinemia.Br J Dermatol 1985;113:339

8. Char DH,et al.Radiation therapy for ocular necrobiotic xanthogranuloma. Arch Ophthalmol1987;105:174

9. Chave TA, et al. Recalcitrant necrobiotic xanthogranuloma responding to pulsed high -dose oral dexamethasone plus maintenance therapy with oral prednisolone. Br J Dermatol 2001;144:158

10. Georgiou S,et al. Inteferon alpha-2a mono therapy for necrobiotic xanthogranuloma.Acta Derm Venereol(Stockh) 1999;79:484

11. Finelli LG, Ratz JL. Plasmapheresis, a treatment modality for necrobiotic xanthogranuloma. J Am Acad Dermatol 1987;17:351

12. Dupre A,Viraben R.Necrobiotic xanthogranuloma: a case without paraproteinemia but with transepithelial elimination. J Cutan Pathol 1988;15(2):116-9 